Article

\title{
Comparative Research on Solar Phase Change Material Storage Wall Systems under Different Summer Working Conditions
}

\author{
Lijie Xu ${ }^{1}$, Jie Ji ${ }^{1, *}$, Chenglong Luo ${ }^{2, *}$, Dan Sun ${ }^{2}$, Jihai Xiong ${ }^{2}$ and Mengyin Liao ${ }^{2}$ \\ 1 Department of Thermal Science and Energy Engineering, University of Science and Technology of China, \\ Hefei 230027, China; lbjmvp@mail.ustc.edu.cn \\ 2 Institute of Energy Research, Jiangxi Academy of Sciences, Nanchang 330096, China; \\ sundansh@163.com (D.S.); xjh6110@vip.sina.com (J.X.); lmy1324@126.com (M.L.) \\ * Correspondence: jijie@ustc.edu.cn (J.J.); xxlong@ustc.edu (C.L.); \\ Tel.: +86-0551-6360-7346 (J.J.); +86-0792-8839-0763 (C.L.)
}

Received: 19 October 2017; Accepted: 14 November 2017; Published: 16 November 2017

\begin{abstract}
To study and analyze the performance characteristics and the effectiveness of the system under practical application scenarios, the present work compares the performance of solar energy phase change material storage wall systems suitable for buildings in hot summer and cold winter regions under different summer working conditions. The experimental facility was installed on light-weight insulation wall and ordinary wall; ventilation conditions of shutting/opening doors and windows, respectively, were set. The experimental facility showed different thermal characteristics when it was installed on insulation wall and on solid wall whether it was vented or not; under vented working condition, the temperature of the external surface of the south-facing wall which attached to the solid wall experimental system was lower, demonstrating that under practical building scenarios the present technology could better reveal its capability of avoiding the overheating issue of the solar heating wall in summer.
\end{abstract}

Keywords: solar energy; building energy efficiency; phase change material; passive cooling

\section{Introduction}

Nowadays, climate change, environmental protection and energy shortage are global significant issues requiring for prompt solution. The greenhouse gases emission generated by energy utilization accounts for $69 \%$ of the global total emissions [1]. Some $30-40 \%$ of the world energy is consumed by buildings, mainly for climatization purposes [2]. Thereby, investigating new technologies that combine clean energy, such as the solar energy, with the building energy consumption is a hot topic for researchers around the globe.

The incorporation and integration of solar energy with phase change material storage wall technology in buildings has many advantages. For example, it can use the limited external surface area of envelope structure of buildings to enhance the overall utilization ratio of solar energy, thereby reducing the percentage of conventional energy and thus realizes building energy conservation. Meanwhile, features such as the small temperature change in phase change process and high phase change latent heat of phase change material (PCM) are used to enhance the heat storage capability of envelope structure of building. This can be helpful in reducing the indoor temperature fluctuation, and improving the indoor thermal comfort conditions [3].

Different types of research studies dealing with the incorporation of PCM in buildings have been conducted. Neeper [4] proposed a system in which PCM was incorporated with the building envelope. It was concluded that the largest storage can be obtained when the phase change temperature 
is close to the average air temperature in the room. Zhou [5] established a south-facing direct-gain room with shape-stabilized phase change material (SSPCM) model and discussed the selection criteria of some parameters such as phase change temperature, and latent heat. Zhang [6] simulated the indoor temperature variation and energy saving performance of buildings constructed with PCM under different ventilation conditions in varying ambient conditions (June to September). Different optimal ventilation schemes were suggested for different climatic conditions. Soares et al. [7] concluded the combination of solar energy technology and PCM storage technology with envelope structure of the building can effectively reduce room temperature fluctuation and enhance thermal comfort. Sun [8] proposed a proposed a mathematical model for the building wall incorporated with PCM, presented calculation methods of energy-saving rate and power-conserving value, created a mathematical model and discussed the usage and investment cycle in different regions. Reddy [9] investigated the thermal performance of roof integrated with PCM. The results showed that using multi-PCM layers of appropriate thickness are more beneficial compared to the single PCM. It was observed that using multiple PCMs a constant comfortable temperature of $\sim 28^{\circ} \mathrm{C}$ can be maintained in the building throughout the day in hot and humid conditions of Chennai, India. Maha [10] proposed a PCM wall combined with light-weight insulation plate to enhance the thermal inertia of the entire wall and the internal thermal comfort. Simulation study was performed using TRNSYS software and results were validated with the experimental study. It was observed that good experimental effects exist in winter and summer, as well as long-term durability. The above mentioned literature shows the positive effect and profound significance of combining PCM and solar energy technology in buildings on the thermal conditions of the space. Gu et al. [11] proposed a heat recovery system using PCMs to recover the rejected heat from air-conditioning systems to produce domestic hot water for washing and bathing. The thermodynamic calculation showed that the integrative energy efficiency ratio of the system can be improved effectively when all rejected sensible and latent heat from air-conditioning systems can be recovered. Saman et al. [12] investigated a roof integrated solar heating system using a PCM storage experimentally and numerically. The results showed that the effect of sensible heat was perceived in the initial periods of melting and freezing processes. A higher inlet air temperature and air flow rate can increase heat transfer rates and shortens the melting time, but a higher air flow rate increased outlet air temperatures. For freezing, a lower inlet air temperature and a higher air flow rate can increase heat transfer rates and shortens the freezing time, but a higher air flow rate reduced outlet air temperatures. Ismail and Henríquez [13] proposed a concept of a window with moving PCM curtains. The window was double sheeted with a gap between the sheets and an air vent at the top corner. The experimental and simulation results showed that the proposed concept of the PCM filled window system is thermally effective, and the green colored PCM is more effective in reducing radiated energy gains. Literature above show the positive effect and profound significance of combining PCM and solar energy technology in buildings.

It is revealed that there exists a large regional discrepancy in indoor thermal environment, the worst performing region being the hot summers and cold winters zone in China [14,15]. To fulfill the heating and cooling/insulation demand during winter and summer seasons that coexists in buildings especially located in regions with hot summers and cold winters, based on the principle of combining solar energy utilization technology and PCM storage technology, the effectiveness of a dual-channel and thermal-insulation-in-the-Middle type Solar PCM storage Wall (MSPCMW) system is analyzed experimentally and discussed.

The analysis is carried out through comparative tests conducted in a hot-box using the south-facing wall as the insulation wall [16]. However, the light-weight insulation wall which has negligible storage capability is used in the comparative hot-box tests, while the actual building walls are mostly solid walls with storage capability. The standard test approach is conducted by shutting doors and windows whereas in actual situation the buildings usually use vented working conditions-keeping the doors and windows open in summer. Hence, some previous experimental work related to this novel system cannot fully reflect the real performance of the working scenarios in summer. To extend the performance characteristics and the effectiveness of the system under practical application scenarios, 
this work compares the performance when the experimental facility is installed on a light-weight insulation wall and ordinary wall, as well as under different ventilation situations, i.e., shutting doors and windows, and opening doors and windows, respectively.

\section{Test Setup and Introduction of Test Approach}

The working principle of dual-channel and thermal-insulation-in-the-middle type solar PCM storage wall (MSPCMW) system is shown in Figure 1. It is mainly composed of PCM wall, thermal insulation wall, interior and exterior flow channels, heat absorbing aluminum plate covered by selective absorption coating, indoor upper and lower vents $(5,6)$, outdoor upper and lower vents $(1,2)$, middle layer upper and lower vents $(3,4)$, glass cover and frame. The system is installed on the south-facing vertical surface of the building. Structural design of dual-channel and thermal insulation layer, appropriate design of vent opening switch, as well as the use of characteristics of PCM help achieving passive heating, heat preservation, heat insulation and cooling functions of buildings. Two operation modes are adopted to realize heating, heat preservation, thermal insulation, and cooling for the demands in different seasons. The operation modes are:

(1) winter operation mode, passive solar heating during daytime and heat preservation in nighttime;

(2) summer operation mode, thermal insulation in daytime and passive cooling in nighttime. The working condition of summer operation mode is introduced as follows:

Heat insulation mode: when the building needs the protection of thermal insulation in daytime, e.g., in summer's daytime, the indoor upper and lower vents $(5,6)$ and the middle layer ones $(3,4)$ shut while the outdoor ones $(1,2)$ open. The combination of ambient wind pressure and thermosiphon pressure forms a circular flow between the external channels and the outdoor air that brings the solar energy absorbed by the aluminum plate back to the environment; meanwhile the inner air channel acts as heat protection between the thermal insulation layer and the south wall of the room. Thus achieving the purpose of reducing building's absorption of solar energy.

Passive cooling mode: when the building needs thermal insulation protection during nighttime, e.g., in summer nighttime, the indoor upper and lower vents $(5,6)$ shut while the middle layer ones $(3,4)$ and the outdoor ones $(1,2)$ open. Primarily under the action of ambient wind pressure, circular flow forms between internal channel and external channel; the relatively cool outdoor air during the nighttime cools down the PCM wall. In this way cold energy can be stored in the PCM wall reducing the indoor temperature.

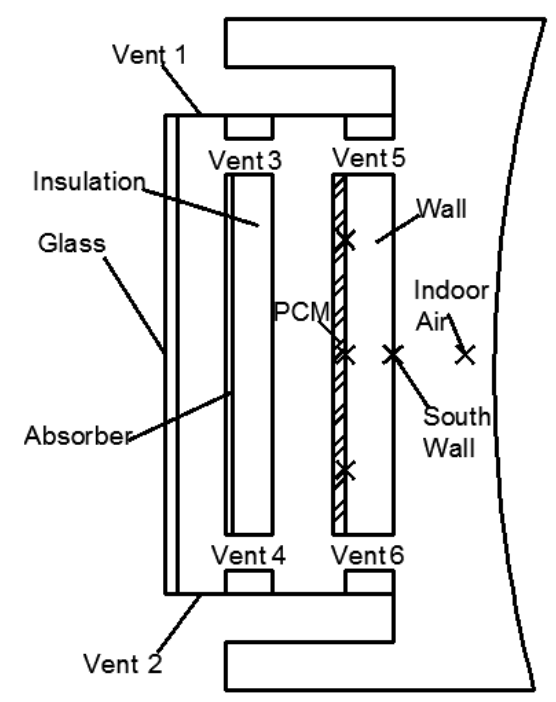

Figure 1. The structural diagram of the test setup. 
The present comparison test is conducted establishing the two experimental test systems on a comparative hot-box using the light-weight insulation wall as south-facing wall and a comparative-hot-box-like hot-box using the brick wall as south facing wall, respectively. The dimensions of both hot box are $3 \mathrm{~m} \times 3 \mathrm{~m} \times 2.6 \mathrm{~m}(L \times W \times H)$. The dimensions of the door and the window are $1.6 \mathrm{~m} \times 0.6 \mathrm{~m}(L \times W)$ and $1 \mathrm{~m} \times 1 \mathrm{~m}(L \times W)$, separately. For brevity, insulation wall test system and solid wall test system indicate the two systems, respectively. Each test system consists of two rooms. The one installed with the present experimental facility is the experimental room, and the other with structures and dimensions consistent with those of the experimental room but without the experimental facility is the control room. Figure $2 a, b$ show the exterior appearances of the insulation wall test system and the solid wall test system, respectively; the structures and the thermal material properties of the walls are listed in Table 1. In each system, the working conditions of closed doors and windows, and opened doors and windows (mentioned as unvented working condition and vented working conditions hereinafter) are compared.

The measurements mainly include the temperature and solar radiation intensity. A conventional copper-constantan thermocouple (accuracy of $\pm 0.5^{\circ} \mathrm{C}$ ) is used for temperature measurements. The configuration of the main temperature monitoring points in the test system are shown in Figures 1 and 3. Figure 1 shows a section view of the structure in which the positions of the points, marked by ' $x$ ', are indoor air temperature (1 point), exterior surface of the wall on which PCM plate is attached ( 3 points evenly distributed along the height) and internal surface of the wall (1 point). Figure 3 shows the locations of the thermocouples on the external surface of PCM plate, marked by ' $\bullet$ ', and the thermocouples on the interior side counterpose those on the exterior side. The measuring system also includes ambient temperature measurement and solar radiation intensity on the south-facing vertical surface obtained by a TBQ-2 pyranometer (Agilent, Hefei, Anhui Province, China). Real-time temperature and radiation data was collected by data acquisition unit.

The plate was wrapped in aluminum and plated with anti-corrosive coating. Each plate measured $0.45 \mathrm{~m} \times 0.3 \mathrm{~m} \times 0.01 \mathrm{~m}(L \times W \times H)$. Its interior components are crystalline hydrate and organic PCM thus it benefits from both phase change materials of hydrate and organic matter [16]. The material properties of the PCM are listed in Table 2.

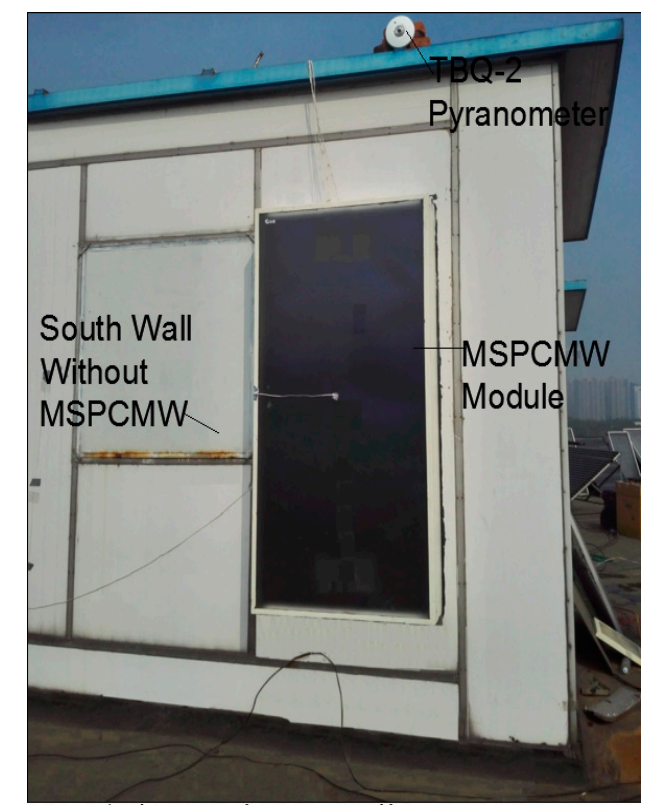

a) the insulation wall test system

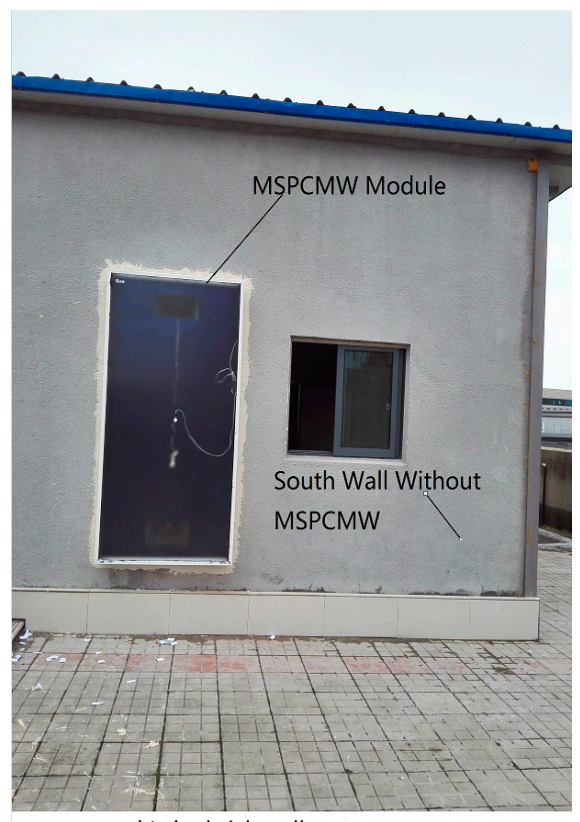

b) the brick wall system

Figure 2. Exterior view of the two test systems: (a) the insulation wall test system and (b) the brick wall test system. 


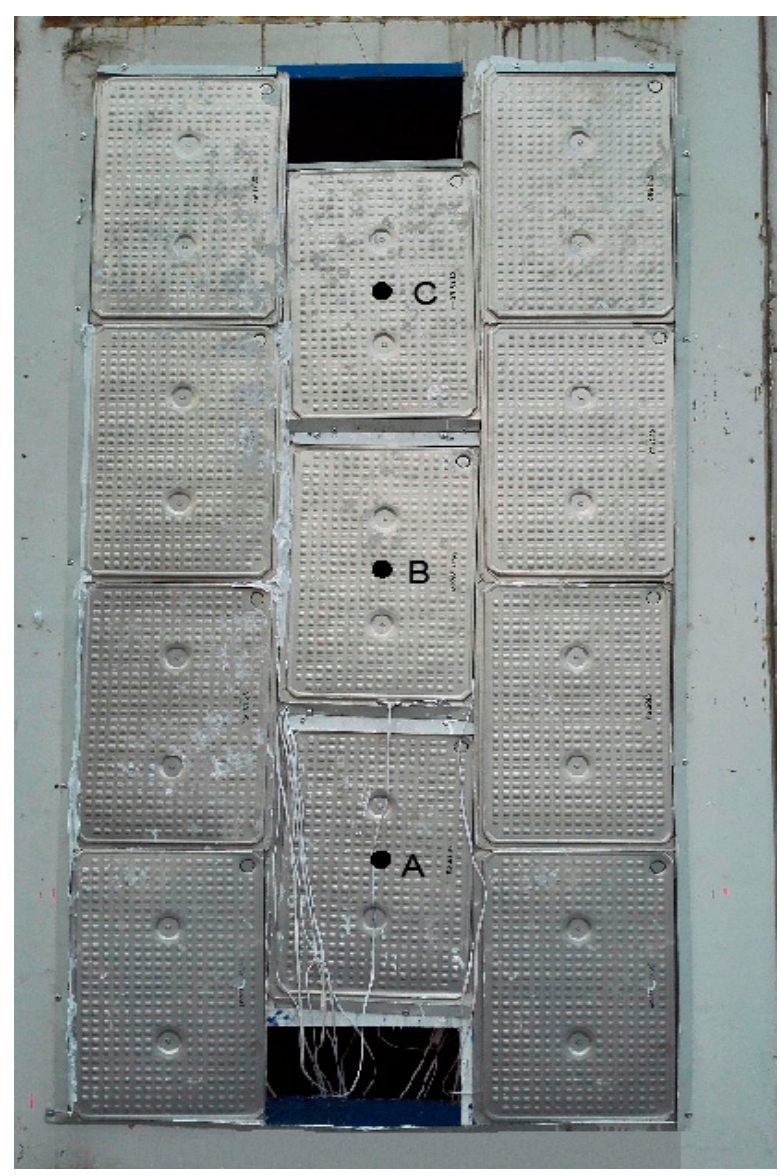

Figure 3. Arrangement of PCM plates and temperature monitoring points.

Table 1. Parameters of the envelope structure of insulation wall and brick wall hot box.

\begin{tabular}{ccccccc}
\hline Layer & Material & $\begin{array}{c}\text { Thickness } \\
(\mathbf{m})\end{array}$ & $\begin{array}{c}\text { Thermal } \\
\text { Conductivity } \\
(\mathbf{W} / \mathbf{m} \cdot \mathbf{K})\end{array}$ & $\begin{array}{c}\text { Density } \\
\left(\mathbf{k g} / \mathbf{m}^{3}\right)\end{array}$ & $\begin{array}{c}\text { Heat Capacity } \\
(\mathrm{J} / \mathbf{k g} \cdot \mathbf{K})\end{array}$ \\
\hline & 1 & Steel Plate & 0.004 & 60.5 & 7854 & 434 \\
\hline & & Polystyrene & $\begin{array}{c}0.1(\text { South } \\
\text { Wall)/0.05 } \\
(\text { other })\end{array}$ & 0.04 & 15 & 434 \\
\hline
\end{tabular}

Table 2. Material properties of the PCM.

\begin{tabular}{ccc}
\hline Properties & Unit & Number \\
\hline Melt Point & ${ }^{\circ} \mathrm{C}$ & $25-27$ \\
Solid Point & ${ }^{\circ} \mathrm{C}$ & $22-24$ \\
Heat storage Capacity (From $17-32{ }^{\circ} \mathrm{C}$ ) & $\mathrm{kJ} / \mathrm{kg}$ & 180 \\
Thermal Conductivity & $\mathrm{W} /(\mathrm{m} \cdot \mathrm{K})$ & 0.6 \\
\hline
\end{tabular}




\section{Experimental Results and Discussions}

\subsection{Test Conditions}

The experiments for the insulation wall test system was conducted from 12-15 September 2017; On 12 and 14 September, unvented working conditions were tested, while on the 13 and 15 September, vented working conditions were tested. In unvented working conditions, door and window were closed, while in vented conditions all were opened. During the tests, the outdoor upper and lower vents opened and the indoor ones shut, and the middle layer ones shut at around 8:50 in the morning during the daytime and opened at around 18:40 in the evening. Figure 4 shows the comparison between two consecutive days, i.e., the 14 th and 15 th. The $T_{\text {Amb }}$ represents the ambient temperature while the $I_{\text {Solar }}$ represents the sun radiation. Based on the picture, the highest ambient temperature was $30.0^{\circ} \mathrm{C}$ on 14 September and $29.5^{\circ} \mathrm{C}$ on 15 September, and average temperature of the ambient air were $25.9^{\circ} \mathrm{C}$ and $25.6{ }^{\circ} \mathrm{C}$ separately. Radiation conditions were similar: the maximum radiation intensities were $476 \mathrm{~W} / \mathrm{m}^{2}$ and $410 \mathrm{~W} / \mathrm{m}^{2}$, and the average of radiation were $150.8 \mathrm{~W} / \mathrm{m}^{2}$ and $118.5 \mathrm{~W} / \mathrm{m}^{2}$, respectively. Hence, the ambient conditions are similar in the tests for both days. Figure 5 presents the comparison of indoor air temperature, where $T_{E \_R}$ and $T_{R \_R}$ indicate room air temperature in experimental room and in control room, respectively.

Concerning solid wall test system, tests were conducted for the three consecutive days (16-18 May 2017) in unvented working condition and consecutive seven days (24-30 May 2017) in vented working condition. In unvented working conditions, door and window were closed, while in vented conditions, door and window were opened. During the tests, the outdoor upper and lower vents opened, the indoor ones shut, and the middle layer ones shut at about 8:50 in the morning in daytime and opened at about 18:40 in the evening. In each of the two tests, a representative day was chosen for comparison (see Figure 6), i.e., 18 and 26 May. The $T_{\text {Amb }}$ represents the ambient temperature and the $I_{\text {Solar }}$ represents the sun radiation. On 18 May, the highest ambient temperature was $32.4{ }^{\circ} \mathrm{C}$ while average temperature was $28^{\circ} \mathrm{C}$. The maximum radiation intensity was $379 \mathrm{~W} / \mathrm{m}^{2}$ while the average radiation was $102.7 \mathrm{~W} / \mathrm{m}^{2}$. On $26 \mathrm{May}$, the highest ambient temperature was $31.5^{\circ} \mathrm{C}$ while average temperature was $26.7^{\circ} \mathrm{C}$. The maximum radiation intensity was $305 \mathrm{~W} / \mathrm{m}^{2}$ while average radiation intensity was $87.6 \mathrm{~W} / \mathrm{m}^{2}$. Figure 7 presents the variation curves of the air node temperatures of experimental room $T_{E_{-} R}$ and control room $T_{R \_R}$ in the two days. Compared with the results of insulation wall test system, the indoor air temperature difference between the vented and unvented condition is larger than the solid wall system.

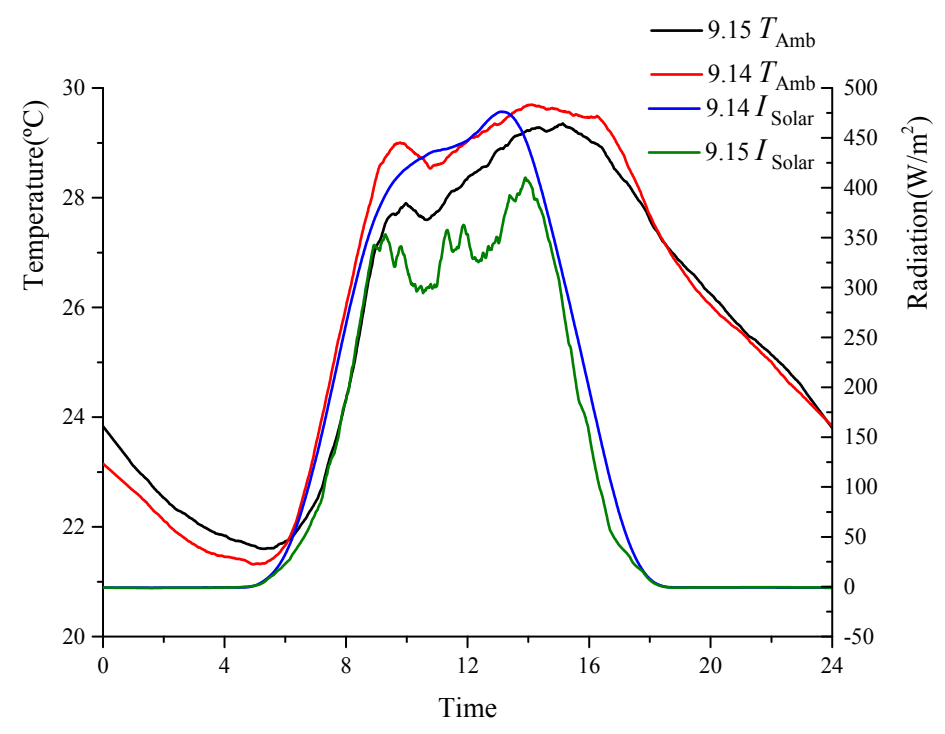

Figure 4. Ambient parameter comparison between 14 and 15 September (insulation wall test system). 


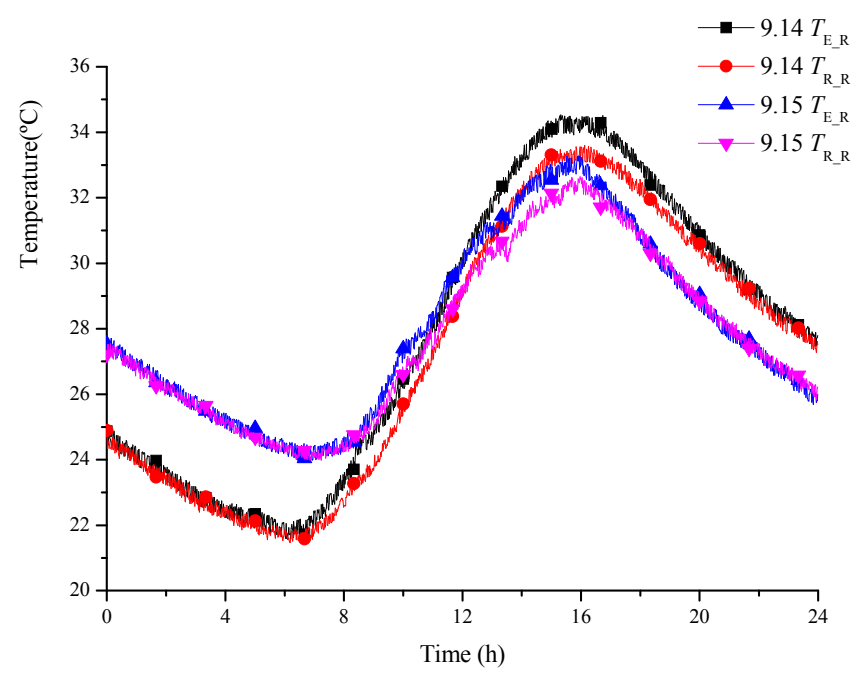

Figure 5. Indoor air temperature comparison between 14 and 15 September (insulation wall test system).

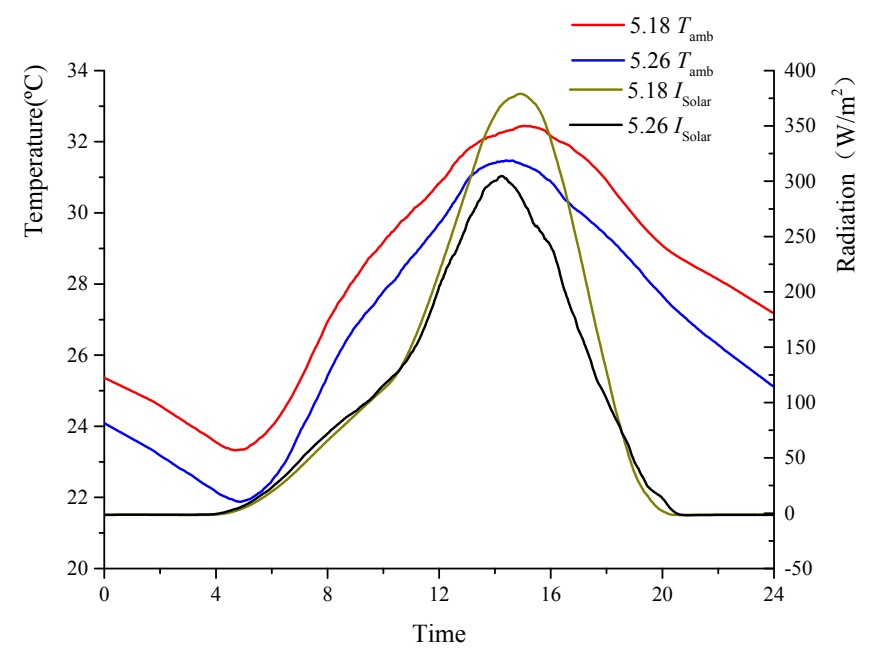

Figure 6. Ambient parameter comparison between 18 and 26 May (solid wall test system).

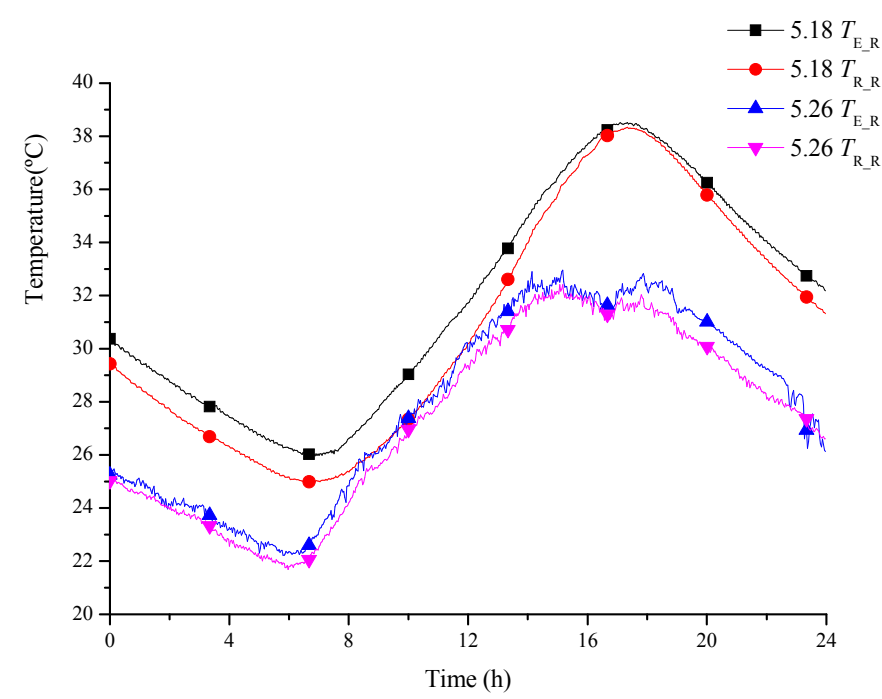

Figure 7. Indoor air temperature comparison between 18 and 26 May (solid wall test system). 


\subsection{Comparison between Two Working Conditions of Insulation Wall Test System}

The comparison of the impact of installing the present experimental facility on the thermal environment of building under vented working condition is analyzed. Figure 8 shows the comparison of the relationship of the south-facing wall temperature of the insulation wall test system. $T_{\mathrm{E} \_ \text {SW_WITH }}$ is temperature of the exterior surface of south-facing wall of experimental room installed with the present experimental facility, $T_{\text {E_SW_WITHOUT }}$ is that of experimental room without the present experimental facility, while $T_{\mathrm{R} \_s w}$ is south wall temperature of control room. The symbolic notation above is also used in the following discussion of the results of solid wall test system. The impact of using vented working condition on $T_{\mathrm{E} \_S W_{-}}$WITHOUT and $T_{\mathrm{R} \_\mathrm{SW}}$ was very slight, but the value of $T_{\mathrm{E} \_ \text {SW_WITH }}$ on 14 September reached its maximum of $43.3^{\circ} \mathrm{C}$ at $14: 47$. On 15 September, the maximum value of $T_{\text {E_SW_WITH }}$ was $42.3^{\circ} \mathrm{C}$ at 15:20. Compared with the results under unvented working condition, the peak value of $T_{\text {E_SW_WITH }}$ had certain reduction and delay in occurrence time. Figure 9 shows how the temperature difference variation between the exterior and the interior surfaces of south-facing wall of the experimental room installed under the two working conditions. The $D_{-} T_{\mathrm{SW}} \mathrm{WITH}_{\mathrm{W}}$ is the temperature difference between outside and inside of south wall with the MSPCMW. The maximum value of $D_{-} T_{\text {SW_WITH }}$ was $10^{\circ} \mathrm{C}$ on 14 September and $9.8^{\circ} \mathrm{C}$ on 15 September, demonstrating that $D_{-} T_{\text {SW_WITH }}$ of insulation wall test system under both unvented and vented working conditions was relatively large.

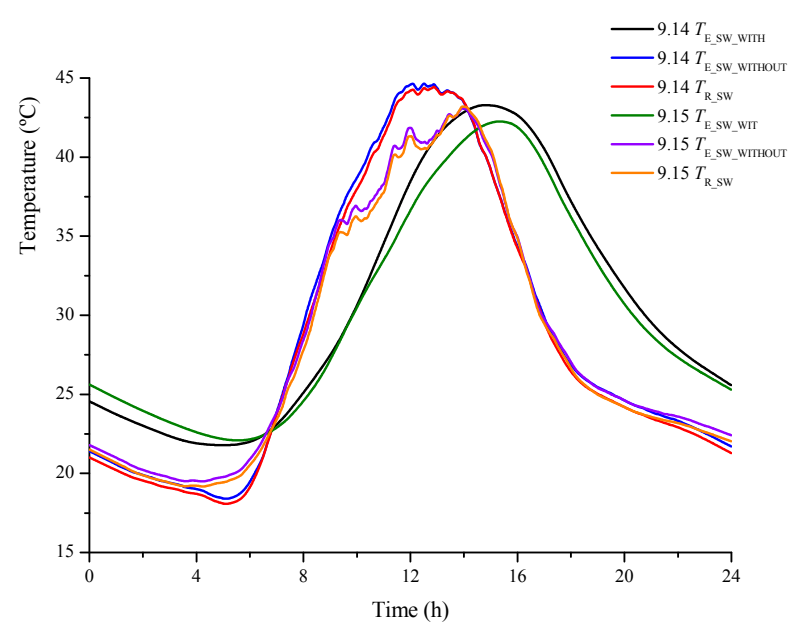

Figure 8. Temperature comparison diagram of south-facing wall.

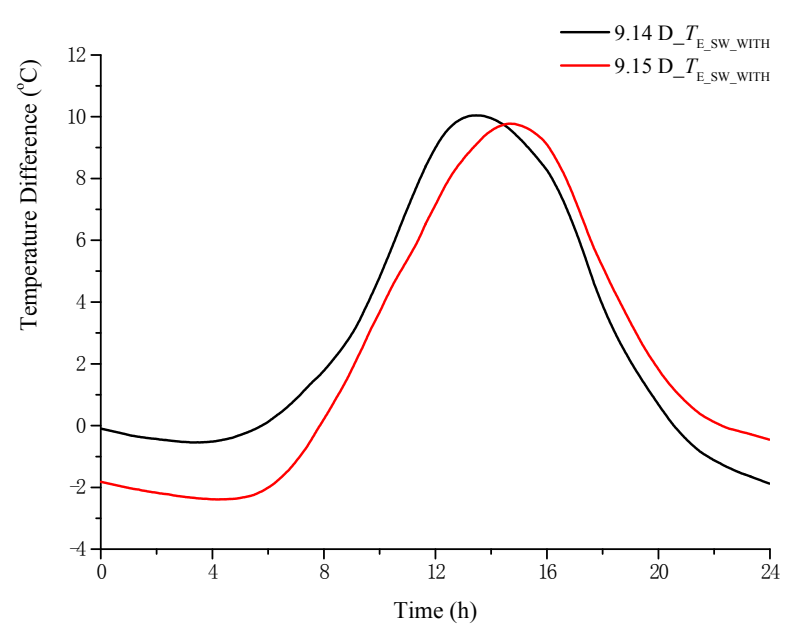

Figure 9. Variation curve of temperature difference between exterior and interior surfaces of south-facing wall of experimental room. 
Figure 10 shows the temperature comparison among upper, middle, and lower surface center points of the PCM plate, and results are tabulated in Table 3. The PCM A, B and C are shown in Figure 3. Regarding the unvented and vented working conditions, distinct thermal stratification phenomenon of PCM plate temperature could be observed along the height direction during the daytime, characterized by high temperature in the upper part and low temperature in the lower part; moreover, the peak temperature of the lower part showed delay in time.

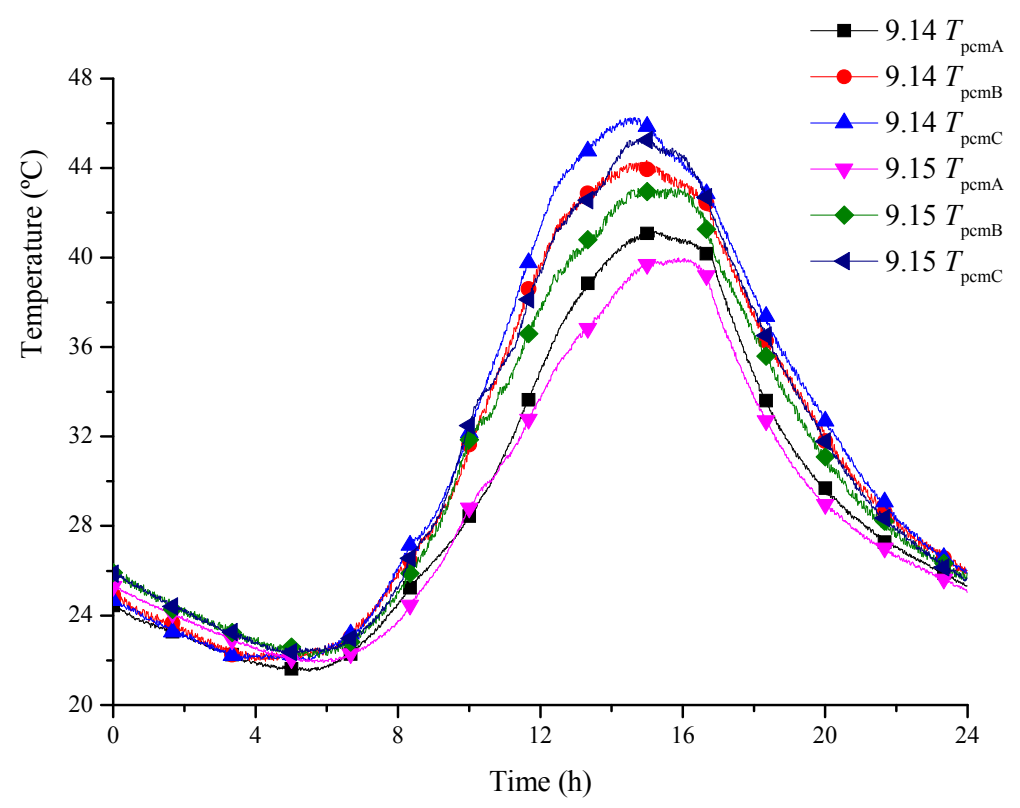

Figure 10. Temperature comparison of PCM plate.

Table 3. Main data of temperature comparison of the PCM plate.

\begin{tabular}{cccccc}
\hline Temperature & $\boldsymbol{T}_{\max }\left({ }^{\circ} \mathbf{C}\right)$ & Time to Reach & $\boldsymbol{T}_{\min }\left({ }^{\circ} \mathbf{C}\right)$ & Time to Reach & $\boldsymbol{T}_{\text {Average }}\left({ }^{\circ} \mathbf{C}\right)$ \\
\hline $9.14 T_{\mathrm{pcmA}}$ & 41.2 & $15: 12$ & 21.5 & $5: 30$ & 29.3 \\
$9.14 T_{\mathrm{pcmB}}$ & 44.3 & $15: 00$ & 20.0 & $4: 18$ & 31.2 \\
$9.14 T_{\mathrm{pcmC}}$ & 46.3 & $14: 40$ & 22.4 & $5: 24$ & 31.8 \\
$9.15 T_{\mathrm{pcmA}}$ & 40.0 & $15: 54$ & 21.9 & $5: 40$ & 28.9 \\
$9.15 T_{\mathrm{pcmB}}$ & 43.1 & $15: 00$ & 22.1 & $5: 30$ & 30.7 \\
$9.15 T_{\mathrm{pcmC}}$ & 45.3 & $15: 03$ & 22.3 & $5: 06$ & 31.5 \\
\hline
\end{tabular}

\subsection{Comparison between Two Working Conditions of Solid Wall Test System}

Figure 11 compares the temperature variation on the exterior surface of south-facing wall of solid wall test system under unvented and vented working conditions, and the results are summarized in Table 4. The $T_{E_{-} \text {SW_WITH }}$ is the temperature of experiment room's south wall with the MSPCMW, the $T_{\text {E_SW_WITHOUT }}$ is the temperature of experiment room's south wall without the MSPCMW and $T_{R_{-} S W}$ is the temperature of south wall of control room. The $T_{\mathrm{E}_{-} S W_{-} W I T H}$ showed a significant reduction compared with $T_{\mathrm{E}_{-} \mathrm{SW}_{-} \text {WITHOUT }}$ and $T_{\mathrm{R} \_\mathrm{SW}}$ under both unvented and vented working conditions. In addition, under unvented working condition, the averages of $T_{\text {E_SW_WITHOUT, }} T_{R_{-}}$SW and $T_{\text {E_SW_WITH }}$ were basically identical, while under vented working condition the average of $T_{\mathrm{E} \_S W \_W I T H}$ was lower than that of $T_{\mathrm{E} \_} \mathrm{SW} \_$WITHOUT or $T_{\mathrm{R} \_} \mathrm{SW}$. 


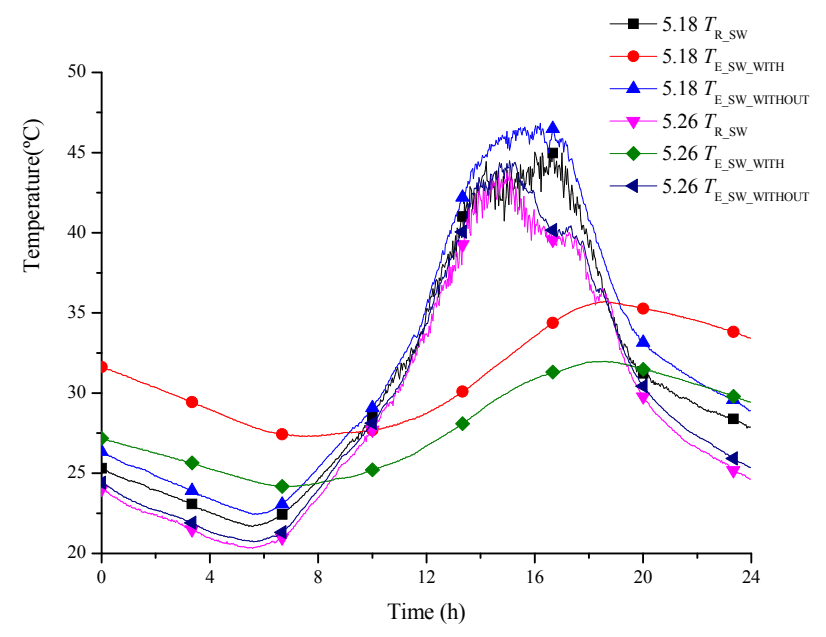

Figure 11. Temperature comparison diagram of south-facing wall.

Table 4. Main data of temperature comparison of south-facing wall.

\begin{tabular}{cccccc}
\hline Temperature & $\boldsymbol{T}_{\max }\left({ }^{\circ} \mathbf{C}\right)$ & Time to Reach & $\boldsymbol{T}_{\min }\left({ }^{\circ} \mathbf{C}\right)$ & Time to Reach & $\boldsymbol{T}_{\text {Average }}\left({ }^{\circ} \mathbf{C}\right)$ \\
\hline $5.18 T_{\text {E_SW_WITH }}$ & 35.7 & $18: 42$ & 27.3 & $7: 36$ & 31.1 \\
$5.18 T_{\text {E_SW_WITHOUT }}$ & 46.8 & $16: 12$ & 22.4 & $5: 38$ & 32.0 \\
$5.18 T_{\text {R_SW }}$ & 45.0 & $16: 00$ & 21.7 & $5: 34$ & 30.8 \\
$5.26 T_{\text {E_SW_WITH }}$ & 32.0 & $18: 36$ & 24.1 & $6: 45$ & 27.8 \\
$5.26 T_{\text {E_SW_LITHOUT }}$ & 44.5 & $15: 05$ & 20.7 & $5: 36$ & 29.7 \\
$5.26 T_{\text {R_SW }}$ & 44.1 & $15: 04$ & 20.3 & $5: 36$ & 29.2 \\
\hline
\end{tabular}

Figure 12 shows the variation curves of the temperature difference between exterior and interior surfaces of the part with the experimental facility installed and the remaining part of south-facing wall of the experimental room. D_T $T_{\text {E_SW_WITH }}$ and $D_{-} T_{\mathrm{E}_{-} S \mathrm{SW}_{-} \text {WITHOUT }}$ is temperature difference between exterior and interior surfaces of south-facing wall of the experimental room installed with and without experimental facility, respectively. From the curves, $D_{-} T_{\mathrm{E} \_ \text {SW_WITHOUT }}$ indicated significant temperature difference under both unvented and vented working conditions, and the peak value was observed as high as $10{ }^{\circ} \mathrm{C}$; however, $D_{-} T_{\mathrm{E}_{-}} \mathrm{SW}_{-}$WITH was close to $0{ }^{\circ} \mathrm{C}$ under both working conditions. This proves that the application of the present facility can make favorable heat protection during the summer time. This may be beneficial for preventing the overheating of the south wall during summer, which is a common issue in the ordinary solar passive heating systems.

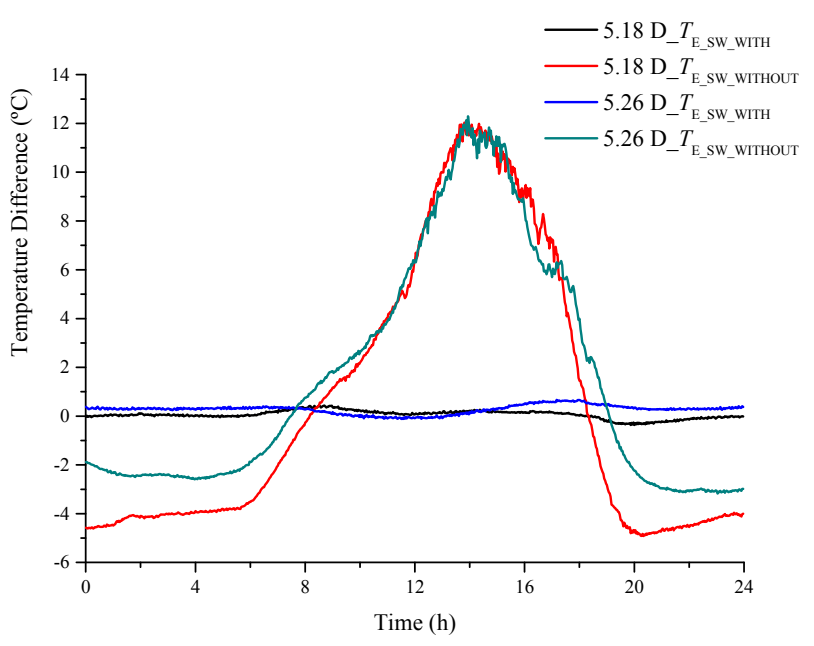

Figure 12. Comparison of temperature difference between exterior and interior surfaces of the wall. 
Figure 13 compares the results of the temperature for the upper, middle, and lower surface center points of the PCM plate of solid wall system, and Table 5 lists the main analyzed results of the PCM plate temperature data. PCM temperature is significantly reduced in vented working condition compared with that in unvented working condition (the average reduction is $2{ }^{\circ} \mathrm{C}$ and the maximum reduction is $3^{\circ} \mathrm{C}$ ); It is also observed the thermal stratification of PCM along the height direction becomes less significant in vented working condition.

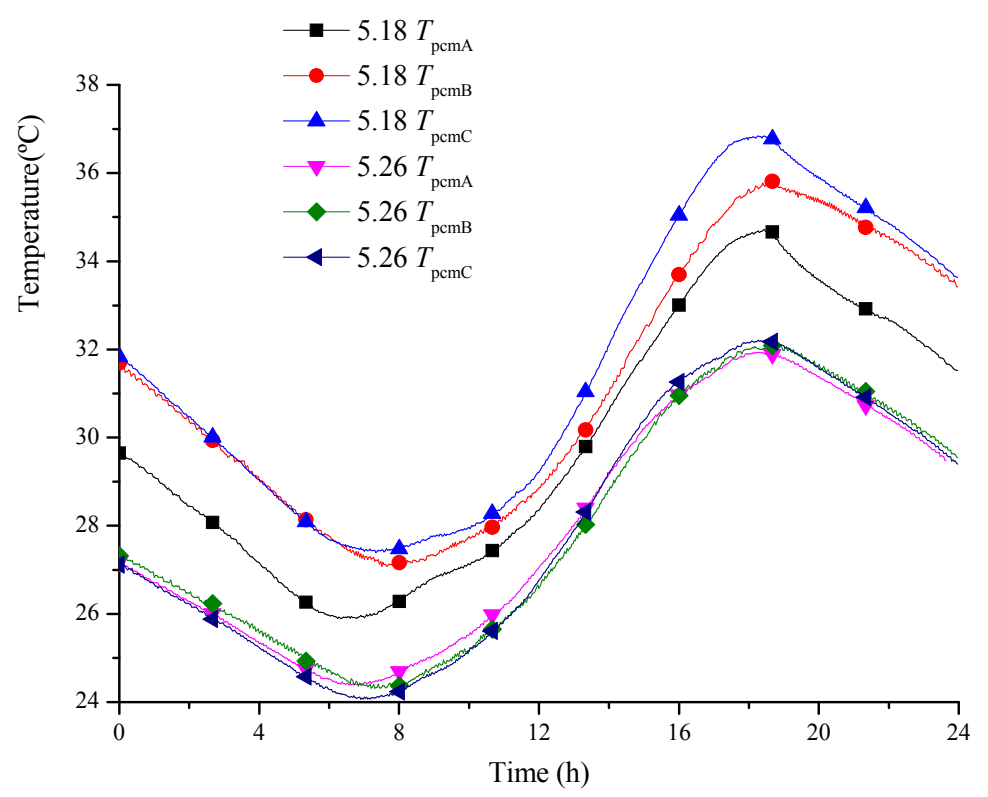

Figure 13. Temperature comparison of the PCM plate.

Table 5. Temperature comparison of the PCM plate.

\begin{tabular}{cccccc}
\hline Temperature & $\boldsymbol{T}_{\max }\left({ }^{\circ} \mathbf{C}\right)$ & Time to Reach & $\boldsymbol{T}_{\min }\left({ }^{\circ} \mathbf{C}\right)$ & Time to Reach & $\boldsymbol{T}_{\text {Average }}\left({ }^{\circ} \mathbf{C}\right)$ \\
\hline $5.16 T_{\mathrm{pcmA}}$ & 34.7 & $18: 25$ & 25.9 & $6: 14$ & 29.9 \\
$5.16 T_{\mathrm{pcmB}}$ & 35.5 & $18: 42$ & 27.0 & $7: 30$ & 31.3 \\
$5.16 T_{\mathrm{pcmC}}$ & 36.8 & $18: 27$ & 27.4 & $7: 14$ & 31.6 \\
$5.26 T_{\mathrm{pcmA}}$ & 31.9 & $18: 10$ & 24.4 & $6: 36$ & 27.9 \\
$5.26 T_{\mathrm{pcmB}}$ & 32.1 & $18: 36$ & 24.3 & $7: 18$ & 27.9 \\
$5.26 T_{\mathrm{pcmC}}$ & 32.2 & $18: 30$ & 24.0 & $6: 54$ & 27.9 \\
\hline
\end{tabular}

Besides, by comparing insulation wall test system and solid wall test system under vented working condition: (1) the maximum of $T_{\mathrm{E} \_ \text {SW_WITH }}$ of insulation wall on 15 September was $42.3^{\circ} \mathrm{C}$, and $T_{\text {E_SW_WITH }}$ of solid wall test system on 26 May was $32.0^{\circ} \mathrm{C}$, while the ambient situations of both days were almost identical. Therefore, the application of the experimental facility in solid wall buildings can keep the heating wall at lower temperature in summer. Therefore, when applying the experimental facility to the building in practical scenarios, the performance of prevention from overheating the wall in summer can be expected to be as good as the test result obtained from the

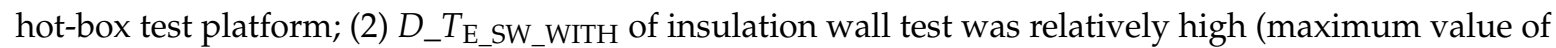
$9.8^{\circ} \mathrm{C}$ ), while that of solid wall test system was nearly ignorable; (3) Thermal stratification of PCM plate surface center temperature along the height direction was weaker in solid wall test system than in insulation wall test system. 


\section{Conclusions}

To study the performance characteristics and effectiveness of applying the system to practical scenarios, the present experimental study compares the performance of installing the experimental facility on a light-weight insulation wall and an ordinary brick wall. In both cases, ventilation working condition of shutting doors and windows, and that of opening doors and windows are set, and the following conclusions are reached:

(1) Test system installed on insulation wall: vented working conditions impacts little on temperature of the exterior surface of south-facing wall of experimental room without the present experimental facility and temperature of the exterior surface of south-facing wall of control room, but a small reduction in peak value and delay in occurrence time of the peak of temperature of the exterior surface of south-facing wall of experimental room with the present experimental facility was observed with respect to unvented working condition. Under both unvented and vented working conditions, temperature difference between exterior and interior surfaces of south-facing wall of the experimental room installed with experimental facility is relatively large, and the PCM plate temperature in daytime shows significant thermal stratification phenomenon along the height direction.

(2) Test system installed on solid wall: under both unvented and vented working conditions, temperature of the exterior surface of south-facing wall of experimental room with the present experimental facility reduced greater than temperature of the exterior surface of south-facing wall of experimental room without the present experimental facility and temperature of the exterior surface of south-facing wall of control room, and temperature difference between exterior and interior surfaces of south-facing wall of the experimental room installed with experimental facility was close to $0{ }^{\circ} \mathrm{C}$. In addition, PCM temperature reduced significantly in vented working condition compared to unvented working condition; meanwhile, PCM temperature in vented working condition showed less significant thermal stratification along the height direction, different from the significant thermal stratification phenomenon in insulation wall test system.

(3) Other comparisons between insulation wall test system and solid wall test system under vented working condition: temperature of the exterior surface of south-facing wall of experimental room with the present experimental facility in solid wall system was lower than in insulation system, demonstrating that applying the present technology in practical building scenarios can better show its performance of preventing from overheating issue of heating wall in summer.

Acknowledgments: This study was sponsored by: (2) the National Science Foundation of China (NSFC), Project No. 51408278, (2) the National Science Foundation of China (NSFC), Project No. 51366004, and (3) the Jiangxi Provincial Key Technology R\&D Program, China, Project No. $20141 B B E 50041$.

Author Contributions: Lijie $\mathrm{Xu}$ did the experiment test and analyzed the experimental data. Jie Ji and Chenglong Luo guided the theoretical and experimental plan formulation. Dan Sun did the experiment test. Jihai Xiong and Mengyin Liao also analyzed the experimental data.

Conflicts of Interest: The authors declare no conflict of interest.

\section{References}

1. International Energy Agency (IEA). IEA Statistics: $\mathrm{CO}_{2}$ Emissions from Fuel Combustion; International Energy Agency (IEA): Paris, France, 2014.

2. Omer, A.M. Energy, environment and sustainable development. Renew. Sustain. Energy Rev. 2008, 12, 2265-2300. [CrossRef]

3. Cabeza, L.F.; Castell, A.; Barreneche, C.; de Gracia, A.; Fernández, A.I. Materials used as PCM in thermal energy storage in buildings: A review. Renew. Sustain. Energy Rev. 2011, 15, 1675-1695. [CrossRef]

4. Neeper, D.A. Thermal dynamics of wallboard with latent heat storage. Sol. Energy 2000, 68, $393-403$. [CrossRef]

5. Zhou, G.; Zhang, Y.; Lin, K.; Xiao, W. Thermal analysis of a direct-gain room with shape-stabilized PCM plates. Renew. Energy 2008, 33, 1228-1236. [CrossRef] 
6. Zhang, Y.; Cui, H.; Tang, W.; Sang, G.; Wu, H. Effect of Summer Ventilation on the Thermal Performance and Energy Efficiency of Buildings Utilizing Phase Change Materials. Energies 2017, 10, 1214. [CrossRef]

7. Soares, N.; Costa, J.J.; Gaspar, A.R.; Santos, P. Review of passive PCM latent heat thermal energy storage systems towards buildings' energy efficiency. Energy Build. 2013, 59, 82-103. [CrossRef]

8. Sun, X.; Zhang, Q.; Medina, M.A.; Lee, K. Energy and economic analysis of a building enclosure outfitted with a phase change material board (PCMB). Energy Convers. Manag. 2014, 83, 73-78. [CrossRef]

9. Reddy, K.S.; Mudgal, V.; Mallick, T.K. Thermal Performance Analysis of Multi-Phase Change Material Layer-Integrated Building Roofs for Energy Efficiency in Built-Environment. Energies 2017, 10, 1367. [CrossRef]

10. Ahmad, M.; Bontemps, A.; Sallée, H.; Quenard, D. Thermal testing and numerical simulation of a prototype cell using light wallboards coupling vacuum isolation panels and phase change material. Energy Build. 2006, 38, 673-681. [CrossRef]

11. Gu, Z.; Liu, H.; Li, Y. Thermal energy recovery of air conditioning system-Heat recovery system calculation and phase change materials development. Appl. Therm. Eng. 2004, 24, 2511-2526. [CrossRef]

12. Saman, W.; Bruno, F.; Halawa, E. Thermal performance of PCM thermal storage unit for a roof integrated solar heating system. Sol. Energy 2005, 78, 341-349. [CrossRef]

13. Ismail, K.A.R.; Henríquez, J.R. Thermally effective windows with moving phase change material curtains. Appl. Therm. Eng. 2001, 21, 1909-1923. [CrossRef]

14. Li, B.; Du, C.; Yao, R.; Yu, W.; Costanzo, V. Indoor thermal environments in Chinese residential buildings responding to the diversity of climates. Appl. Therm. Eng. 2017, 129, 693-708. [CrossRef]

15. Lin, B.; Wang, Z.; Liu, Y.; Zhu, Y.; Ouyang, Q. Investigation of winter indoor thermal environment and heating demand of urban residential buildings in China's hot summer-Cold winter climate region. Build. Environ. 2016, 101, 9-18. [CrossRef]

16. Luo, C.; Xu, L.; Ji, J.; Liao, M.; Sun, D. Experimental study of a modified solar phase change material storage wall system. Energy 2017, 128, 224-231. [CrossRef]

(C) 2017 by the authors. Licensee MDPI, Basel, Switzerland. This article is an open access article distributed under the terms and conditions of the Creative Commons Attribution (CC BY) license (http:/ / creativecommons.org/licenses/by/4.0/). 